\title{
Characterization of a New Subgroup of Rhizoctonia solani Anastomosis Group 1 (AG-1-ID), Causal Agent of a Necrotic Leaf Spot on Coffee
}

\author{
Achmadi Priyatmojo, Verma E. Escopalao, Naomi G. Tangonan, Cecilia B. Pascual, \\ Haruhisa Suga, Koji Kageyama, and Mitsuro Hyakumachi
}

First author: The United Graduate School of Agricultural Science, Gifu University, Yanagido 1-1, Gifu 501-1193, Japan; second and third authors: College of Agriculture, University of Southern Mindanao, Kabacan, Cotabato, Philippines; fourth author: Plant Pathology Laboratory, Institute of Plant Breeding, University of the Philippines at Los Banos, College, Laguna 4031, Philippines; fifth author: Molecular Genetics Research Center, Gifu University, Yanagido 1-1, Gifu 501-1193, Japan; and sixth and seventh authors: Laboratory of Plant Disease Science, Faculty of Agriculture, Gifu University, Yanagido 1-1, Gifu 501-1193, Japan.

Current address of A. Priyatmojo: Department of Entomology and Plant Pathology, Faculty of Agriculture, Gadjah Mada University, Yogyakarta 55281, Indonesia.

Accepted for publication 17 July 2001.

\begin{abstract}
Priyatmojo, A., Escopalao, V. E., Tangonan, N. G., Pascual, C. B., Suga, H., Kageyama, K., and Hyakumachi, M. 2001. Characterization of a new subgroup of Rhizoctonia solani anastomosis group 1 (AG-1-ID), causal agent of a necrotic leaf spot on coffee. Phytopathology 91:1054-1061.

A new foliar disease on coffee leaves was observed in Mindanao, Philippines, in 1996. The symptoms appeared as large circular or irregularly shaped necrotic areas with small circular necrotic spots $(1 \mathrm{~mm}$ or less in diameter) usually found around the periphery of the large necrotic areas. Rhizoctonia solani was consistently isolated from these diseased coffee leaves. Isolates obtained were multinucleate ( 3 to 12 nuclei per hyphal cell), had an optimum temperature for hyphal growth at $25^{\circ} \mathrm{C}$, prototrophic for thiamine, and anastomosed with tester isolates belonging to $R$. solani anastomosis group 1 (AG-1). Mature cultures on potato dextrose agar (PDA) were light to dark brown. Sclerotia, light brown to
\end{abstract}

ABSTRACT

Rhizoctonia solani Kühn [teleomorph = Thanatephorus $\mathrm{cucu}$ meris (A. B. Frank) Donk] is a destructive soilborne pathogen on a large number of plant species $(1,31)$. $R$. solani causes many diseases such as seed decay, damping-off, stem cankers, root rots, fruit decay, and foliage diseases (19). By their multinucleate hyphae, $R$. solani are distinguished from uninucleate and binucleate Rhizoctonia spp. (8,31).

$R$. solani is a heterogeneous species composed of at least 14 anastomosis groups (AGs) including AG-1 through AG-13 and AG-BI (bridging isolate) $(4,5,31)$. The AG grouping of $R$. solani is based on hyphal anastomosis with known AG tester isolates. Isolates of $R$. solani that anastomose with tester isolates are assigned to the same AG, whereas isolates from different AGs generally do not anastomose with each other (4,22-24). In the 14 recognized AGs, at least 24 subgroups have been reported $(6,9,10$, $16,21,31)$.

Among the 14 AGs, AG-1 has many plant-pathogenic isolates obtained from a range of hosts $(11,23,24,31)$. Based on cultural morphology and pathogenicity, isolates within AG-1 have been divided into three subgroups: AG-1-IA (rice-sheath blight), AG-1-IB (web-blight), and AG-1-IC (damping-off) $(9,11,24,31)$.

Corresponding author: M. Hyakumachi; E-mail address: hyakumac@cc.gifu-u.ac.jp

Publication no. P-2001-0827-02R

(C) 2001 The American Phytopathological Society brown, were formed on the surface of PDA and covered the whole mature colony culture. Individual sclerotia often aggregated into large clumps ( 3 to $8 \mathrm{~mm}$ in diameter) and their color was brown to dark brown. In pathogenicity tests, isolates from coffee caused necrotic symptoms on coffee leaves, whereas isolates of AG-1-IA (not isolated from coffee), 1-IB, and 1-IC did not. The results of analyses of restriction fragment length polymorphism of ribosomal DNA internal transcribed spacer, random amplified polymorphism DNA, and fatty acid profiles showed that $R$. solani isolates from coffee are a population of AG- 1 different from AG-1-IA, 1-IB, and 1-IC. These results suggest that $R$. solani isolates from coffee represent a new subgroup distinct from AG-1-IA, 1-IB, and 1-IC. A new subgroup ID (AG-1-ID) is proposed.

Additional keywords: Coffea arabica, differentiation, fatty acid methyl ester, Thanatephorus cucumeris.
Recently, molecular techniques such as DNA base sequence homology (6), restriction fragment length polymorphism (RFLP) of rDNA internal transcribed spacer (ITS) $(15,36,38)$, and random amplified polymorphic DNA polymerase chain reaction (RAPDPCR) $(7,36,37)$ have been used to differentiate isolates of $R$. solani within and between AGs. Liu and Sinclair (15) differentiated AG-1 into six intraspecific groups (AG-1-IA, 1-IB, 1-IC, 1-ID, 1-IE, and 1-IF) based on RFLP of rDNA-ITS and isozyme compositions.

Fatty acid analysis has been employed to differentiate closely related isolates of $R$. solani $(17,18,33-35)$. Stevens-Johnk and Jones (35) reported that AG-1-IC was clearly differentiated from AG-1-IA and AG-1-IB using fatty acid analysis, although AG-1-IA and AG-1-IB were not differentiated with this technique. However, isolates of AG-2 representing AG-2-1, AG-2-2-IIIB, AG-2-2-IV, AG-2-2-LP, and AG-2-3 were clearly differentiated based on fatty acid profiles $(18,34)$. Baird et al. (2) also successfully differentiated isolates of AG-4 from AG-7 using fatty acid profiles.

In 1996, foliar disease was found on the coffee leaves in Mindanao, Philippines. The symptoms appeared as large circular or irregularly shaped necrotic areas and small circular necrotic spots of $1 \mathrm{~mm}$ or less in diameter. The small necrotic spots were usually found around the periphery of the large necrotic areas (Fig. 1). From these diseased coffee leaves, $R$. solani was consistently isolated onto acidified water agar (AWA). The symptom of 
this new disease is different from foliar blight symptom of coffee caused by AG-1-IA, which also was observed in the Philippines (26). RFLP of rDNA-ITS and RAPD analyses confirmed that $R$. solani causing foliar blight of coffee belonged to AG-1-IA (27).

The objective of the study was to characterize isolates of $R$. solani, causal agent of necrotic leaf spot of coffee. $R$. solani isolates from coffee were studied for anastomosis behavior, cultural appearance, nuclear conditions, pathogenicity, hyphal growth rate at different temperatures, and induction of the teleomorph. RFLP of rDNA-ITS and RAPD analyses were carried out to ascertain genetic diversity among isolates. In addition, fatty acid analysis also was used to compare isolates of $R$. solani from coffee with isolates of AG-1-IA, 1-IB, and 1-IC. Partial accounts of this study have been published $(28,29)$.

\section{MATERIALS AND METHODS}

Characteristics of isolates. Small pieces $\left(5 \times 5 \mathrm{~mm}^{2}\right)$ of coffee leaves were cut from the margins of diseased tissue, soaked in $0.5 \%$ sodium hypochlorite solution $(\mathrm{NaOCl})$ for $2 \mathrm{~min}$, rinsed three times with sterile distilled water (SDW), and dried on sterilized filter paper (Whatman No. 1). Small pieces of leaf were placed on AWA $(\mathrm{pH} 4.5)$ with 1 drop of $10 \%$ lactic acid and incubated at $25^{\circ} \mathrm{C}$ in the dark. After 2 to 3 days, cultures were examined microscopically at a magnification of $\times 400$. Rhizoctonialike fungi were hyphal-tipped and transferred to test tube slants of potato dextrose agar (PDA) and stored at $4{ }^{\circ} \mathrm{C}$.

The number of nuclei per cell was determined on cultures grown on sterilized glass slides aseptically coated with $2 \%$ water agar (13). Mycelium was stained with safranin $\mathrm{O}$ and $3 \% \mathrm{KOH}$ (3) and examined microscopically at $\times 400$.

AG determinations were done according to Kronland and Stanghellini's clean glass slide technique (13). Tester isolates of AG-1 through 11 and AG-BI were used. Anastomosis reactions were observed and assessed according to categories described by Carling (4).

For descriptions of cultures, a 7-mm mycelial disk, cut from the margin of an actively expanding young culture of a coffee isolate on PDA, was placed in the center of 9 -cm petri dish containing PDA and incubated at $25^{\circ} \mathrm{C}$ in the dark. The appearance of cultures was evaluated 4 and 25 days after incubation. Selected isolates representing the three known subgroups of AG-1 were included for comparison.

Radial growth rate of coffee isolates and selected isolates representing the three known subgroup of AG-1 were determined at 5, $10,15,20,25,30$, and $35^{\circ} \mathrm{C}$ on PDA. Measurement was started $12 \mathrm{~h}$ after placing petri dishes in the incubator to allow the diffusion of temperature to the agar. Colony radius was measured at 24-h intervals until the colony reached the edge of the petri dish. Each treatment was replicated three times, and the experiment was repeated once.

The thiamine requirement for the growth of coffee isolates was determined with the glucose-asparagine (GA) medium as described by Ogoshi and Ui (25). Erlenmeyer flasks containing a GA medium with or without $10^{-5} \mathrm{M}$ thiamine hydrochloride, were inoculated with 7-mm-diameter mycelial disk of selected isolates of coffee isolates. Isolates representing AG-1-IC (prototrophic) were included for comparison. Each treatment was replicated three times, and the experiment was repeated once.

Induction of teleomorphs. Coffee isolates were induced to sporulate on yeast extract/glucose/agar (25:12.5:20, wt/wt/wt in 1 liter of SDW) and water agar by using soil overlay (22) and fungistasis (12) techniques, respectively. Isolate F-1 of AG-1-IC, which sporulates readily, was selected for comparison.

Pathogenicity test. Virulence of four selected coffee isolates was determined on detached young leaves of arabic coffee (Coffea arabica L.). Two isolates each, representing AG-1-IA (not isolated from coffee), 1-IB, and 1-IC, were included for comparison. A 7-mm-diameter mycelial disk from the margin of a 3-day-old colony grown on PDA was placed in the center of the adaxial side of the leaf. Inoculated leaves were kept in moist boxes and placed at $28^{\circ} \mathrm{C}$ in the dark. Disease severity was determined 3 weeks after inoculation on a subjective scale ranging from 0 to 4 , in which $0=$ healthy, no lesion; $1=$ one lesion $<2 \mathrm{~mm} ; 2=$ two to four lesions $<5 \mathrm{~mm} ; 3=$ four to eight lesions $<10 \mathrm{~mm}$; and $4=$ more than eight lesions, diameter $>10 \mathrm{~mm}$ or all leaf tissue dead. Additionally, virulence of isolates was tested on cucumber seedlings using the water agar method described below. Seeds of cucumber (Cucumis sativus L. cv. Jibai) were surface disinfected with $70 \%$ ethanol for $1 \mathrm{~min}$, soaked in $2 \% \mathrm{NaOCl}$ with 3 drops of Tween 20 (polyoxyethylene sorbitan monolaurate) for $30 \mathrm{~min}$, and rinsed three times with SDW. The seeds were pregerminated for 2 days at $25^{\circ} \mathrm{C}$ between two layers of sterilized filter paper (Whatman No. 1) soaked in SDW. Five seedlings were transferred to $2 \%$ AWA and kept for 2 days in the growth chamber (12-h photoperiod and daytime illuminance of approximately $250 \mu \mathrm{E} \mathrm{m}^{-2} \mathrm{~s}^{-1}$ ) at $25^{\circ} \mathrm{C}$. For each isolate, a 5-mm-diameter mycelial disk taken from the advancing margin of a 3-day-old PDA culture was inoculated onto the hypocotyl of each of five seedlings. The plates were kept in the same growth chamber and maintained for 14 days. A disease severity index was determined according to the following rating scale of 0 to 4 , in which $0=$ healthy, no lesion on the hypocotyl; $1=$ one or two light brown lesions of $<0.25 \mathrm{~mm} ; 2=$ light brown lesions of $<0.5 \mathrm{~mm}$ and water-soaked areas covering $<10 \%$ of the hypocotyl; 3 = light to dark brown lesions $>1.0 \mathrm{~mm}$ which coalesced with other lesions and water-soaked areas covering $>10$ to $<100 \%$ of the hypocotyl (leaves not yet wilted and hypocotyl still firm and upright); and $4=$ collapsed hypocotyl plus wilted leaves or dead seedlings. Each treatment was replicated four times, and the experiment was repeated once.

RFLP of rDNA-ITS and RAPD analyses. A total of 34 isolates of $R$. solani were used in this study (Table 1). Cultures for DNA extraction were grown in $20 \mathrm{ml}$ of potato dextrose broth (PDB) for 4 days at $25^{\circ} \mathrm{C}$ without shaking. The mycelia were

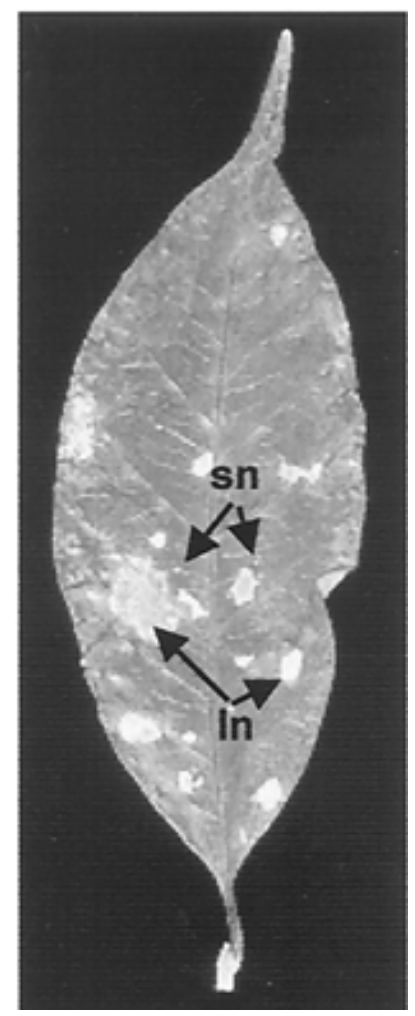

Fig. 1. Necrosis in coffee leaf caused by the newly described Rhizoctonia solani subgroup anastomosis group 1 (AG-1-ID). The symptoms consist of small necrosis (sn) and large necrosis (ln). 
vacuum-filtered, rinsed several times with distilled water, lyophilized, and stored at $-80^{\circ} \mathrm{C}$ until use.

The extraction of DNA was conducted according to the procedure described by Lee and Taylor (14). Lyophilized mycelia were powdered with a sterile mortal and pestle, placed into two $1.7-\mathrm{ml}$ microcentrifuge tubes, suspended in $600 \mu \mathrm{l}$ of extraction buffer (10 mM Tris-HCl, pH 7.5, 100 mM EDTA, 0.5\% sodium dodecyl sulfate, and $100 \mathrm{mM} \mathrm{LiCl}$ ), and incubated at $50^{\circ} \mathrm{C}$ for $15 \mathrm{~min}$ in a water bath. Samples were centrifuged and the aqueous phases were extracted twice with $600 \mu \mathrm{l}$ of phenol/chloroform/isoamyl alcohol (25:24:1, vol/vol/vol). After centrifugation, DNA was precipitated by adding $600 \mu \mathrm{l}$ of isopropyl alcohol into the aqueous phase. Pellets were rinsed with $70 \%$ ethanol, vacuum dried for $30 \mathrm{~min}$, and redissolved in $100 \mu \mathrm{l}$ of TE buffer $(10 \mathrm{mM}$ Tris- $\mathrm{HCl}$, $\mathrm{pH}$ 8.0, and 0.1 mM EDTA). DNA was pooled and $100 \mu \mathrm{l}$ of TE buffer was added after incubation overnight. DNA was treated with $2 \mu \mathrm{l}$ of RNase, incubated at $37^{\circ} \mathrm{C}$ for $60 \mathrm{~min}$, and extracted sequentially with $500 \mu \mathrm{l}$ of Tris-saturated phenol, $500 \mu \mathrm{l}$ of phenol/ chloroform/isoamyl alcohol, $500 \mu \mathrm{l}$ of chloroform/isoamyl alcohol $(24: 1, \mathrm{vol} / \mathrm{vol})$, and $500 \mu \mathrm{l}$ of diethyl-ether by centrifugation. The aqueous phase was then combined with $500 \mu \mathrm{l}$ of isopropyl alcohol and placed on ice for $10 \mathrm{~min}$. Pellets were washed with $70 \%$ ethanol, dried under vacuum, and dissolved in $50 \mu \mathrm{l}$ of TE buffer. DNA was quantified with a spectrophotometer (Amersham Pharmacia Biotech, Buckinghamshire, England). DNA samples were stored at $4^{\circ} \mathrm{C}$ until use.

The universal primers ITS1 and ITS4 were used to amplify the ITS regions as described by White et al. (39). A total volume of $50 \mu \mathrm{l}$ of reaction mixture contained $200 \mathrm{ng}$ of DNA template, 50 pmol of each primer, 1.25 units of rTaq DNA polymerase, $100 \mathrm{mM}$ dNTP mixture, and $1 \times$ PCR buffer $(10 \mathrm{mM}$ Tris- $\mathrm{HCl}$, pH 8.3, $50 \mathrm{mM} \mathrm{KCl}$, and $15 \mathrm{mM} \mathrm{MgCl}$ ) (Takara Shuzo Co. Ltd., Kusatsu, Japan). The reaction mixture was overlaid with 1 drop of

TABLE 1. Isolates of Rhizoctonia solani used in this study

\begin{tabular}{|c|c|c|c|}
\hline Subgroup & Isolate & Host & Origin \\
\hline \multirow[t]{12}{*}{ 1-IA } & RsR2 & Oryza sativa & Philippines \\
\hline & 53 & Coffea arabica & Philippines \\
\hline & 54 & Coffea arabica & Philippines \\
\hline & 55 & Coffea arabica & Philippines \\
\hline & 56 & Coffea arabica & Philippines \\
\hline & RRG 97-1 & Oryza sativa & Japan \\
\hline & 42 & Zea mays & Philippines \\
\hline & 51 & Rottboellia exaltata & Philippines \\
\hline & R6 & Oryza sativa & Japan \\
\hline & $\mathrm{R} 10$ & Lolium perenne & Japan \\
\hline & R59 & Oryza sativa & Japan \\
\hline & R146 & Sorghum bicolor & Japan \\
\hline \multirow[t]{7}{*}{ 1-IB } & TR 22 & Agrostis palustris & Japan \\
\hline & R102 & Oryza sativa & Japan \\
\hline & $\mathrm{R}-31$ & $\ldots{ }^{\mathrm{z}}$ & Japan \\
\hline & La France 1 & Pyrus communis & Japan \\
\hline & 110.1 & Pyrus communis & Japan \\
\hline & 110.4 & Pyrus communis & Japan \\
\hline & 110.10 & Pyrus communis & Japan \\
\hline \multirow[t]{6}{*}{$1-\mathrm{IC}$} & 189 & Brassica oleracea & USA \\
\hline & F-1 & Beta vulgaris & Japan \\
\hline & $\mathrm{F}-4$ & Beta vulgaris & Japan \\
\hline & P-1 & Beta vulgaris & Japan \\
\hline & P-10 & Beta vulgaris & Japan \\
\hline & Rh28 & Beta vulgaris & Japan \\
\hline \multirow[t]{9}{*}{ 1-ID (new) } & RCP 1 & Coffea arabica & Philippines \\
\hline & RCP 3 & Coffea arabica & Philippines \\
\hline & RCP 5 & Coffea arabica & Philippines \\
\hline & RCP 7 & Coffea arabica & Philippines \\
\hline & RCP 9 & Coffea arabica & Philippines \\
\hline & RCP 11 & Coffea arabica & Philippines \\
\hline & RCP 13 & Coffea arabica & Philippines \\
\hline & RCP 15 & Coffea arabica & Philippines \\
\hline & RCP 21 & Coffea arabica & Philippines \\
\hline
\end{tabular}

z Unknown. mineral oil prior to PCR to prevent evaporation. The reaction was conducted with a DNA thermal cycler (Perkin-Elmer Cetus Instruments, Norwalk, CT), and amplification conditions were an initial denaturation at $94^{\circ} \mathrm{C}$ for $3 \mathrm{~min}$, followed by 30 cycles of denaturation at $94^{\circ} \mathrm{C}$ for $1 \mathrm{~min}$, annealing at $59^{\circ} \mathrm{C}$ for $1 \mathrm{~min}$, and extension at $72^{\circ} \mathrm{C}$ for $2 \mathrm{~min}$ with the final extension at $72^{\circ} \mathrm{C}$ for $3 \mathrm{~min}$. PCR products were washed with $50 \mu \mathrm{l}$ of chloroform, precipitated with $3 \mathrm{M}$ sodium acetate and $95.5 \%$ ethanol at $-80^{\circ} \mathrm{C}$ for $30 \mathrm{~min}$, and centrifuged. Pellets were dried under vacuum and resuspended in $50 \mu \mathrm{l}$ of TE buffer. The PCR products were examined by electrophoresis on a $2 \%$ LO3 agarose gel (Takara Shuzo). Gel was stained with ethidium bromide and visualized under UV light.

For RFLP of rDNA-ITS analysis, genome DNA samples were digested separately with restriction enzymes EcoRI, HinfI, MboI, HaeIII, HhaI, and $A l u \mathrm{I}$ at $37^{\circ} \mathrm{C}$, and TaqI at $65^{\circ} \mathrm{C}$ for $6 \mathrm{~h}$ under buffer conditions recommended by the manufacturers (Takara Shuzo). Samples were electrophoresed into 3\% NuSieve 3:1 agarose gel (FMC BioProduct, Rockland, ME) in TAE buffer. A molecular marker (50-bp DNA ladder) (Life Technologies Inc., Gaithersburg, MD) was used as reference in each gel. Gels were stained with ethidium bromide and visualized under UV light.

Twenty-eight primers (Takara Shuzo) were tested, and the six best (P-14, 5'-CCACAGCACG-3'; R-28, 5'-ATGGATCCGC-3'; Rc-09, 5'-GATAACGCAC-3'; OPR-04, 5'-CCCGTAGCAC-3'; OPR-06, 5'-GTCTACGGCA-3'; and OPE-07, 5'-AGATGCAGCC-3') were selected for further study in RAPD analysis. The RAPD reactions were carried out in a $50-\mu 1$ reaction mixture contained $50 \mathrm{ng}$ of genomic DNA, 50 pmol of each primer, 1.25 units rTaq DNA polymerase, $100 \mathrm{mM}$ dNTP mixture and, $1 \times$ PCR buffer (10 mM Tris-HCl, $\mathrm{pH} 8.3,50 \mathrm{mM} \mathrm{KCl}$, and $\left.15 \mathrm{mM} \mathrm{MgCl}_{2}\right)$. The PCR conditions were programmed with a DNA thermal cycler (Perkin-Elmer Cetus Instruments). Amplification conditions were an initial denaturation at $94^{\circ} \mathrm{C}$ for $3 \mathrm{~min}$, followed by 40 cycles of denaturation at $94^{\circ} \mathrm{C}$ for $1 \mathrm{~min}$, annealing at $35^{\circ} \mathrm{C}$ for $1 \mathrm{~min}$, and extension at $72^{\circ} \mathrm{C}$ for 2 min with the final extension at $72^{\circ} \mathrm{C}$ for $3 \mathrm{~min}$. The reaction mixture was overlaid with 1 drop of mineral

TABLE 2. Estimation of restriction fragment lengths of seven enzymes on the ribosomal DNA internal transcribed spacer 1 of isolates of Rhizoctonia solani anastomosis group 1 (AG-1) and coffee isolates

\begin{tabular}{|c|c|c|c|c|}
\hline \multirow[b]{2}{*}{ Enzyme } & \multicolumn{4}{|c|}{ Restriction fragment length (base pair) ${ }^{\mathrm{z}}$} \\
\hline & 1-IA & $1-\mathrm{IB}$ & $1-\mathrm{IC}$ & 1 -ID (new group) \\
\hline EcoRI & $\begin{array}{l}390 \\
330\end{array}$ & $\begin{array}{l}370 \\
360\end{array}$ & $\begin{array}{l}380 \\
310\end{array}$ & $\begin{array}{l}375 \\
365\end{array}$ \\
\hline HaeIII & $\begin{array}{r}520 \\
130 \\
70 \\
\ldots\end{array}$ & $\begin{array}{r}535 \\
125 \\
70 \\
\ldots\end{array}$ & $\begin{array}{r}400 \\
120 \\
100 \\
70\end{array}$ & $\begin{array}{r}540 \\
130 \\
70 \\
\ldots\end{array}$ \\
\hline HinfI & $\begin{array}{l}370 \\
350\end{array}$ & $\begin{array}{r}365 \\
\ldots\end{array}$ & $\begin{array}{l}360 \\
330\end{array}$ & $\begin{array}{r}370 \\
\ldots\end{array}$ \\
\hline$M b o \mathrm{I}$ & $\begin{array}{r}260 \\
210 \\
150 \\
60 \\
40\end{array}$ & $\begin{array}{r}275 \\
250 \\
145 \\
60 \\
\ldots\end{array}$ & $\begin{array}{r}250 \\
240 \\
140 \\
60 \\
\ldots\end{array}$ & $\begin{array}{r}280 \\
250 \\
150 \\
60 \\
\ldots\end{array}$ \\
\hline $\operatorname{Taq} \mathrm{I}$ & $\begin{array}{r}370 \\
290 \\
60\end{array}$ & $\begin{array}{r}370 \\
300 \\
60\end{array}$ & $\begin{array}{r}365 \\
265 \\
60\end{array}$ & $\begin{array}{r}370 \\
310 \\
60\end{array}$ \\
\hline HhaI & $\begin{array}{l}370 \\
350\end{array}$ & $\begin{array}{l}385 \\
345\end{array}$ & $\begin{array}{r}345 \\
\ldots\end{array}$ & $\begin{array}{l}390 \\
350\end{array}$ \\
\hline AluI & $\begin{array}{r}510 \\
210 \\
\ldots \\
\ldots\end{array}$ & $\begin{array}{r}355 \\
210 \\
100 \\
65\end{array}$ & $\begin{array}{r}500 \\
190 \\
\ldots \\
\ldots\end{array}$ & $\begin{array}{r}365 \\
200 \\
110 \\
65\end{array}$ \\
\hline
\end{tabular}

${ }^{\mathrm{z}}$ Fragment length was estimated by comparison with 50-bp DNA ladder for purposes of comparison among isolates. The values do not reflect absolute base pair fragment length. 1-IA, 1-IB, 1-IC, and 1-ID are $R$. solani AG-1IA, 1-IB, 1-IC, and the newly described 1-ID, respectively. 
oil prior to PCR to prevent evaporation. PCR products were washed with $50 \mu \mathrm{l}$ of chloroform and under phases were removed. RAPD products were examined by electrophoresis on $2 \%$ LO3 agarose gel. A molecular marker (100-bp DNA ladder) was used as reference. Gels were stained with ethidium bromide and visualized under UV light. For data analysis, only the reproducible and distinct bands were taken into account. A DNA polymorphism was identified when a band was present in one isolate but absent in the other. The presence and absence of bands were scored as 1 and 0 , respectively. The data generated from six primers for each isolate were pooled and a genetic similarity matrix was calculated based on the method of simple matching coefficient (30). The resulting matrix was analyzed using heuristic searches with branch swapping, tree bisection reconnection algorithms in parsimony analysis using phylogenetic analysis using parsimony (PAUP 4.0b1; Sinaeur Associates Inc., Sunderland, MA) with step-wise additions. Uninformative characters were ignored. Bootstrapping (1,000 bootstrap replicates) was used to determine confidence in the branches of phylogenetic trees.

Fatty acid analysis. The thirty-four isolates of AG-1 used in fatty acid analysis, representing AG-1-IA, 1-IB, 1-IC, and coffee isolates, are listed in Table 1. Seven-millimeter-diameter mycelial disks from the margin of actively expanding young cultures (3-days incubation) on PDA were placed in 9-cm petri dishes containing PDB amended with $50 \mathrm{mg} /$ liter of streptomycin sulfate and incubated at $25^{\circ} \mathrm{C}$ for 4 days in the dark. The mycelia were vacuum-filtered, rinsed several times with distilled water, lyophilized, and stored at $-80^{\circ} \mathrm{C}$ until use.
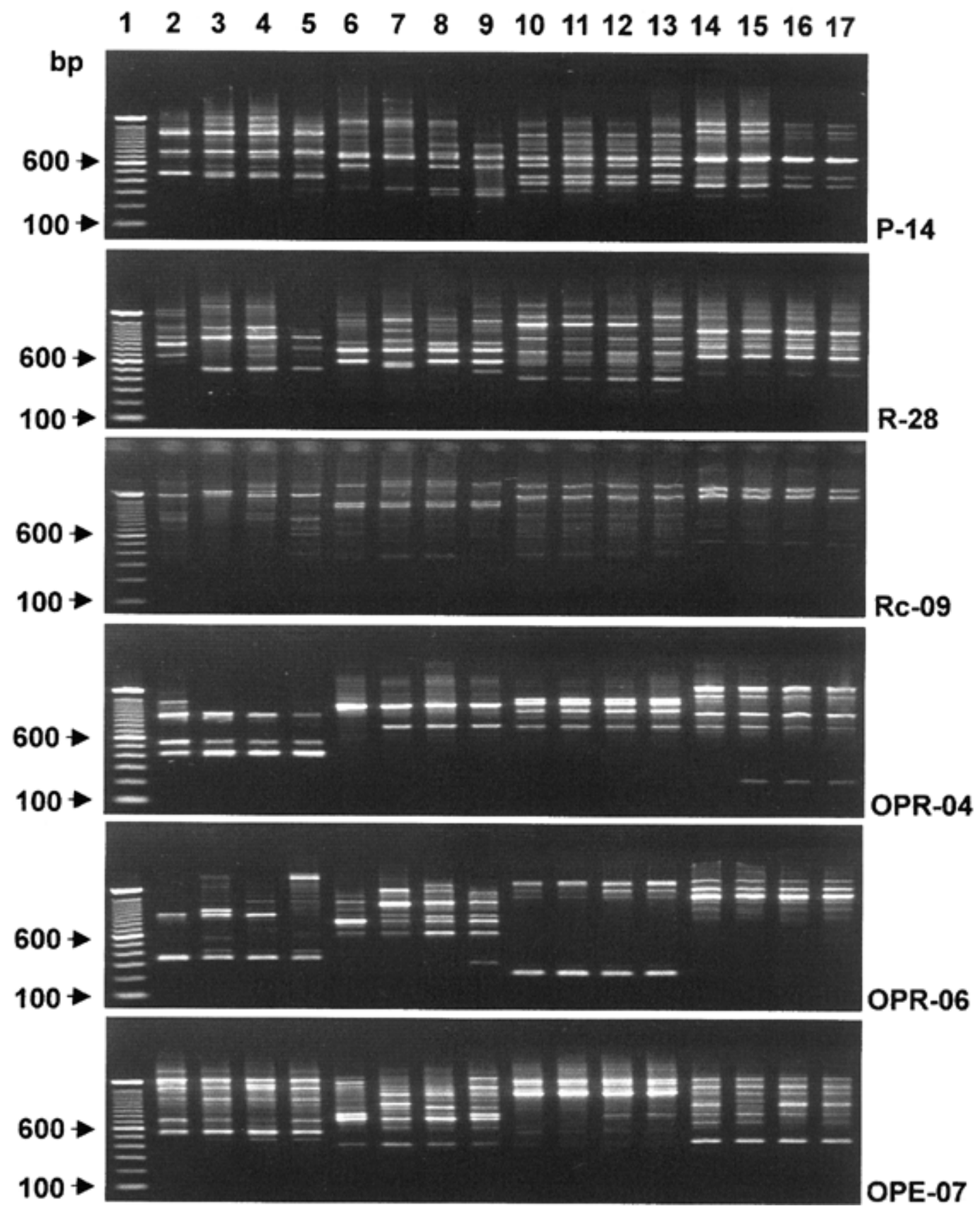

Fig. 2. Random amplified polymorphic DNA analysis of isolates of Rhizoctonia solani anastomosis group 1 (AG-1) and the newly described R. solani subgroup AG-1-ID obtained from coffee leaves using six primers. Lane 1, 100-bp DNA ladder; lanes 2 through 5, representing isolates of AG-1-IA; lanes 6 through 9, representing isolates of AG-1-IB; lanes 10 through 13, representing isolates of AG-1-IC; and lanes 14 through 17, representing isolates of AG-1-ID obtained from coffee leaves. 
Cellular fatty acids were extracted according to the modified method of Matsumoto et al. and Matsumoto and Matsuyama (17, 18). Thirty milligrams of extracted mycelia were methylated with $0.5 \mathrm{ml}$ of $5 \% \mathrm{HCl}$-methanol $(\mathrm{vol} / \mathrm{vol})$ and incubated at $100^{\circ} \mathrm{C}$ for $3 \mathrm{~h}$ in a sealed glass tube. After cooling at room temperature, fatty acid methyl ester (FAME) derivatives were washed with $1 \mathrm{ml}$ of distilled water to remove $\mathrm{HCl}$, extracted with $2 \mathrm{ml}$ of $n$-hexane, and centrifuged at 3,000 rpm for $10 \mathrm{~min}$. The upper phase (solvent phase) was transferred to a new glass tube and concentrated with nitrogen gas. One hundred microliters of $n$-hexane was added in the glass tube and FAME derivatives were stored at $-20^{\circ} \mathrm{C}$ until use.

FAMEs were analyzed using a GC-18A gas chromatograph (Shimadzu Co., Japan) fitted with a Hicap CPB20 fused silica capillary column $(25 \mathrm{~m} \times 0.22 \mathrm{~mm})$ and equipped with a flame

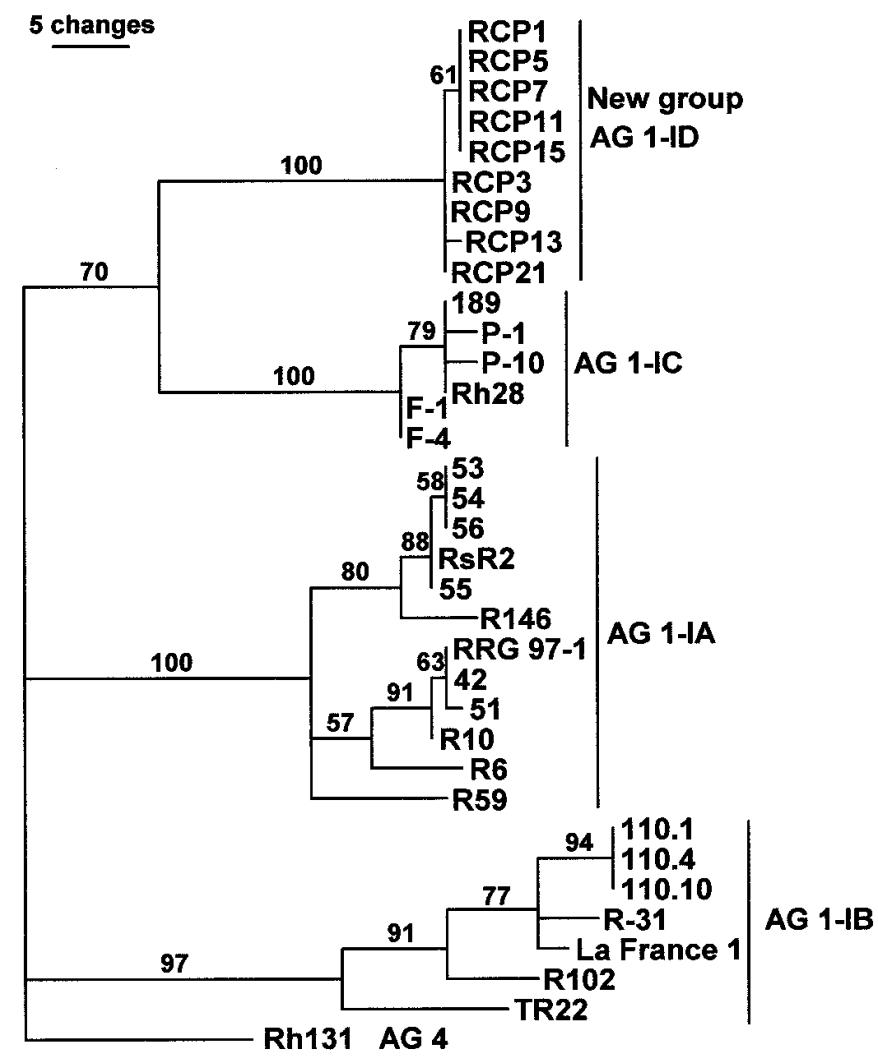

Fig. 3. One of four most parsimonious trees based on 95 characters of banding patterns of random amplified polymorphic DNA using primers P-14, R-28, Rc-09, OPR-04, OPR-06, and OPE-07 of isolates of Rhizoctonia solani anastomosis group (AG) 1-IA, AG-1-IB, AG-1-IC, and the newly described AG-1-ID. The tree is rooted to AG-4 isolate Rh131. Bootstrap values (1,000 replicates) greater than $50 \%$ are indicated above the branches. ionization detector. Nitrogen was used as the carrier gas and its pressure was maintained at $70 \mathrm{kPa}$. The temperature program was initiated at $160^{\circ} \mathrm{C}$ and increased at $1{ }^{\circ} \mathrm{C}$ per min to a final temperature of $220^{\circ} \mathrm{C}$. FAMEs were identified by comparing their retention times with those of standards from a commercial FAME mixture (Funakoshi Co., Japan) containing straight chain saturated fatty acids from $\mathrm{C} 1$ to $\mathrm{C} 20$. FAMEs were expressed as percentage of total fatty acids in samples. Each isolate was replicated three times.

Principal component analysis (Excel Statistics, SSRI Co. Ltd., Tokyo, Japan) was used to determine the amount of variability among isolates. The average linkage cluster analysis (Excel Statistics) was used to determine the relatedness among the three known subgroups of AG-1 and coffee isolates. Data were subjected to analysis of variance, and means were separated according to Tukey's studentized-range procedure (32). Where necessary, percent data were transformed to arcsine square root values to normalize the variance prior to analysis.

\section{RESULTS}

Characteristics of isolates. $R$. solani was consistently isolated from both small and large necrotic areas of the diseased coffee leaves. Coffee isolates were multinucleate and contained 3 to 12 nuclei with the average of 5.7 nuclei per hyphal cell. Coffee isolates of $R$. solani anastomosed and showed $\mathrm{C} 2$ anastomosis reaction with the tester isolates belonging to AG-1-IA, 1-IB, and $1-\mathrm{IC}$, but did not anastomose with tester isolates representing AG-2 through AG-11 and AG-BI.

The mycelia of coffee isolates grown on PDA was white after 4-days incubation, but after 25-days incubation, the color had turned to light brown or brown. At first, mycelia grew on the agar surface, but as cultures aged, mycelia grew into the agar. Sclerotia, light brown to brown, were formed on the surface of PDA and covered the whole mature culture. Individual sclerotia were often aggregating into large clumps (3 to $8 \mathrm{~mm}$ in diameter) and they were brown to dark brown. Sclerotia were coarse and subspheroid.

Hyphal growth rate of coffee isolates and isolates of AG-1-IA, 1-IB, and 1-IC was similar. The optimum temperature for hyphal growth of coffee isolates and $\mathrm{AG}-1-\mathrm{IA}$ was $25^{\circ} \mathrm{C}$, whereas those of $\mathrm{AG}-1-\mathrm{IB}$ and $\mathrm{AG}-1-\mathrm{IC}$ was $30^{\circ} \mathrm{C}$. None of the isolates grew at $5^{\circ} \mathrm{C}$, and all grew slowly at $35^{\circ} \mathrm{C}$.

The growth ratio of coffee isolates grown in GA, with or without thiamine, was approximately the same and ranged from 0.9 to 1.3 , indicating they are prototrophic for thiamine of the isolates. Growth ratio of an isolate of AG-1-IC (prototrophic for thiamine) was 1.0.

Induction of teleomorphs. None of the coffee isolates sporulated using soil overlay or fungistasis techniques. In contrast, isolate F-1 of AG-1-IC sporulated 4 days after inoculation using the soil overlay technique but did not sporulate with the fungistasis technique.

TABLE 3. Percent composition of cellular fatty acids of Rhizoctonia solani anastomosis group 1 (AG-1) representing 1-IA, 1-IB, I-IC, and the newly described 1-ID after 4 days incubation in potato dextrose broth ${ }^{\mathrm{x}}$

\begin{tabular}{|c|c|c|c|c|c|c|c|c|c|c|}
\hline \multirow[b]{2}{*}{ Subgroup $^{\mathrm{y}}$} & \multicolumn{10}{|c|}{ Fatty acid $(\%)^{\mathrm{z}}$} \\
\hline & $14: 0$ & $15: 0$ & $16: 0$ & $\begin{array}{l}16: 1 \\
\text { cis } 9\end{array}$ & $17: 0$ & $\begin{array}{l}17: 1 \\
\text { cis } 9\end{array}$ & $18: 0$ & $\begin{array}{l}18: 1 \\
\text { cis } 9\end{array}$ & $\begin{array}{c}18: 2 \\
\text { cis } 9,12\end{array}$ & $\begin{array}{c}18: 3 \\
\text { cis } 9,12\end{array}$ \\
\hline $1-\mathrm{IA}$ & $0.34 \mathrm{a}$ & $0.36 \mathrm{a}$ & $8.98 \mathrm{a}$ & $0.79 \mathrm{a}$ & $0.26 \mathrm{~b}$ & $0.18 \mathrm{~b}$ & $1.49 \mathrm{~b}$ & $8.15 \mathrm{a}$ & $77.87 \mathrm{c}$ & $0.82 \mathrm{a}$ \\
\hline $1-\mathrm{IB}$ & $0.58 \mathrm{~b}$ & $0.60 \mathrm{~b}$ & $11.42 \mathrm{~b}$ & $1.09 \mathrm{~b}$ & $0.11 \mathrm{a}$ & $0.06 \mathrm{a}$ & $0.99 \mathrm{a}$ & $11.05 \mathrm{~b}$ & $72.98 \mathrm{~b}$ & $1.09 \mathrm{~b}$ \\
\hline $1-\mathrm{IC}$ & $0.57 \mathrm{~b}$ & $0.65 \mathrm{~b}$ & $15.14 \mathrm{c}$ & $0.93 \mathrm{ab}$ & $0.17 \mathrm{a}$ & $0.17 \mathrm{~b}$ & $1.86 \mathrm{~b}$ & $18.83 \mathrm{c}$ & $60.61 \mathrm{a}$ & $1.06 \mathrm{ab}$ \\
\hline 1-ID (new) & $0.72 \mathrm{c}$ & $0.62 \mathrm{~b}$ & $13.03 \mathrm{bc}$ & $1.05 \mathrm{~b}$ & $0.30 \mathrm{~b}$ & $0.15 \mathrm{~b}$ & $2.75 \mathrm{c}$ & $9.53 \mathrm{ab}$ & $70.25 b$ & $1.60 \mathrm{c}$ \\
\hline
\end{tabular}

x Potato dextrose broth was amended with $50 \mathrm{mg}$ liter ${ }^{-1}$ of streptomycin sulfate. Cultures were incubated at $25^{\circ} \mathrm{C}$ in the dark.

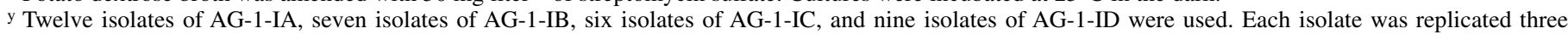
times.

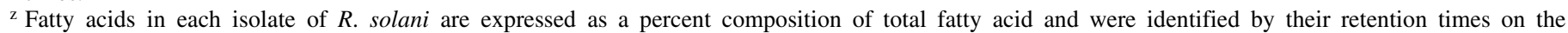
chromatogram. Values in the same column followed by the same letter are not significantly different according to Tukey's studentized-range test $(P=0.05)$. 
Pathogenicity test. Four selected isolates of $R$. solani from coffee caused necrosis on coffee leaves similar to the symptom of the diseased samples from the fields, with disease severity ranging from 2.5 to 3. Neither the control nor isolates of AG-1-IA (not isolated from coffee), 1-IB, and 1-IC caused necrosis on coffee leaves. $R$. solani was reisolated from artificially inoculated diseased coffee leaves to fulfill Koch's postulates. In contrast to disease severity on coffee leaves, all treatments except the control caused disease on cucumber seedlings. Coffee isolates infected cucumber seedlings grown on water agar in petri dish, as well as isolates of AG-1-IA and 1-IB. Virulence of coffee isolates was significantly different $(P=0.05)$ only from isolates $\mathrm{F}-1$ of AG-1-IC (data not shown).

RFLP of rDNA-ITS analysis. The rDNA-ITS region including 5.8S gene was amplified using PCR. The length of rDNA-ITS of coffee isolates, isolates of AG-1-IA, 1-IB, and 1-IC, was estimated as $0.74,0.72,0.73$, and $0.69 \mathrm{~kb}$, respectively (data not shown). Restriction endonuclease digest patterns of PCR-amplified rDNA-ITS using enzymes EcoRI, HinfI, MboI, HaeIII, HhaI, AluI, and TaqI had the same size product among isolates within each subgroup but differed from subgroup to subgroup (Table 2). Coffee isolates and isolates of AG-1-IB were uncut by enzyme HinfI, whereas those of AG-1-IA and AG-1-IC were cut into two fragments. The enzyme HhaI digested isolates of AG-1-IA, 1-IB, and coffee isolates into two fragments but did not cut fragments of isolates of AG-1-IC. Three fragments with different sizes were observed in all isolates of AG-1-IA, 1-IB, 1-IC, and coffee isolates digested with enzyme TaqI. Fragments of isolates of AG-1-IA, 1-IB, and coffee isolates were cut into three fragments, but four in isolates of AG-1-IC using enzyme HaeIII. Two fragments were observed in isolates of AG-1-IA, 1-IB, 1-IC, and coffee isolates using enzyme EcoRI. The enzyme $M b o$ I digested isolates of AG-1-IB, 1-IC, and coffee isolates into four fragments but five fragments in isolates of AG-1-IA. Isolates of AG-1-IA and 1-IC were cut into two fragments by AluI, whereas isolates of AG-1-IB and coffee isolates were cut into four fragments (Table 2).

RAPD analysis. The DNA was amplified using primers P-14, R-28, Rc-09, OPR-04, OPR-06, and OPE-07 in single primer reactions. The number of amplified products generated by each primer varied between 1 and 11 (Fig. 2). In the complete data set of RAPD analysis of isolates of AG-1-IA, 1-IB, 1-IC, and coffee isolates, there were 114 aligned characters of which 95 characters were informative. Four most parsimonious trees of 189 steps were found with a consistency index of 0.6129 , a retention index of 0.9051 , and a rescaled consistency index of 0.5548 . Isolate Rh131 of $R$. solani AG-4 was selected as an outgroup taxon, rooting the tree at an internal node with basal polyotomy. In the ingroup taxa, the inferred clade containing coffee isolates was well supported, as was the clade containing isolates of AG-1-IC but not with isolates of AG-1-IA or AG-1-IB (Fig. 3). Coffee isolates were clustered together and were quite distinct from isolates of AG-1-IA, 1-IB, and 1-IC. Isolates of AG-1-IA, 1-IB, and 1-IC were separately clustered according to their subgroups. Each of the branches with bootstrap support was found in each of the four most parsimonious trees (Fig. 3).

Fatty acid analysis. Ten fatty acids including myristic (14:0), pentadecanoic (15:0), palmitic (16:0), palmitoleic (16:1 cis9), heptadecanoic (17:0), 9-heptadecenoic (17:1 cis9), stearic (18:0), oleic (18:1 cis 9$)$, linoleic $(18: 2$ cis 9,12$)$, and linolenic $(18: 3$ cis 9,12$)$ were present in all isolates of AG-1 and coffee isolates used in this study (Table 3 ).

Linoleic was the major fatty acids found in all isolates of $R$. solani AG-1, which constituted 56.8 to $81.2 \%$ of the cellular fatty acid content (data not shown). Palmitic, oleic, and linoleic accounted for 94.9 to $97.0 \%, 95.0$ to $96.1 \%, 93.5$ to $95.4 \%$, and 91.8 to $93.8 \%$ of whole-cell fatty acid content in isolates of AG-1-IA, 1-IB, 1-IC, and coffee isolates, respectively (data not shown).

The fatty acid composition among the three known subgroups of AG-1 and coffee isolates was qualitatively similar, however, quantitative differences were observed (Table 3). In coffee isolates, for example, percent compositions of myristic, stearic, and linolenic were significantly higher $(P=0.05)$ than those of AG-1IA, 1-IB, and 1-IC. Percent compositions of myristic, pentadecanoic, palmitic, palmitoleic, stearic, and linolenic in coffee isolates were significantly $(P=0.05)$ higher than those of AG-1-IA, whereas those of linoleic in coffee isolates were significantly $(P=$ 0.05) lower than those of AG-1-IA. Moreover, percent compositions of myristic, heptadecanoic, 9-heptadecenoic, stearic, and linolenic in coffee isolates were significantly $(P=0.05)$ higher than those of AG-1-IB. Between coffee isolates and AG-1-IC, percent compositions of myristic, heptadecanoic, and stearic were significantly $(P=0.05)$ higher, whereas those of oleic, linoleic, and linolenic were significantly $(P=0.05)$ lower (Table 3$)$.

Principal component analysis constructed on the basis of 10 fatty acids found showed that coffee isolates were distinct from AG-1-IA, 1-IB, and 1-IC. On the other hand, AG-1-IA and AG-1-IB were not clearly differentiated (Fig. 4). The dendrogram generated from the average linkage cluster analysis showed that coffee isolates were clustered with AG-1-IA and 1-IB at Euclidean distance of 2.5. They were further clustered with AG-1-IC at Euclidean distance of 7.1. AG-1-IA and 1-IB were clustered at Euclidean distance of 1.6 (Fig. 5).

\section{DISCUSSION}

The symptoms of Rhizoctonia disease on coffee leaves consist of small and large necrotic spots. The study on infection by basidiospores of AG-2-3 on soybean by Naito et al. (21) found stroma-like structure as one characteristic of infection by basidiospore on the leaf surface, but this structure was not found on coffee leaves. The symptoms on coffee leaves tend to be similar to infection by basidiospores of $R$. solani in described diseases on other hosts (20), and therefore, the symptoms suggest the possibility of basidiospore infection of coffee leaves. However, we were not able to generate basidiospores in the laboratory with soil overlay or fungistasis techniques, and none have been observed on coffee leaves in nature. AG-1-IA causes foliar blight of coffee in

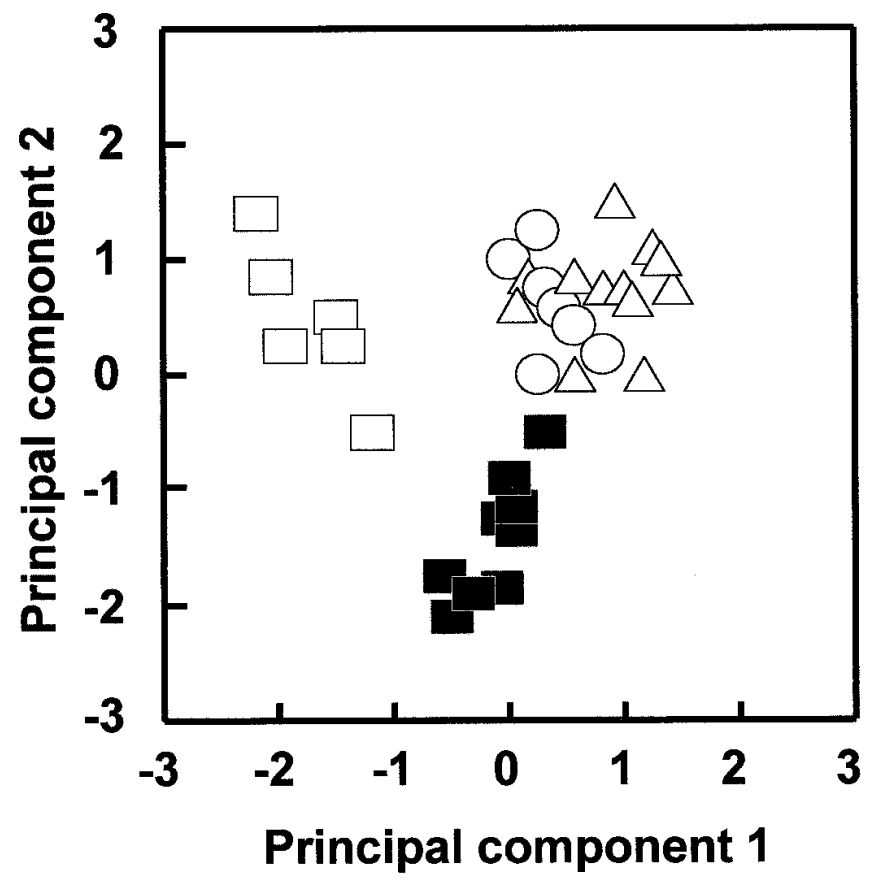

Fig. 4. Plot of the first two principal components derived from percent composition of all detected fatty acids of Rhizoctonia solani anastomosis group 1 (AG-1) isolates, representing AG-1-IA $(\Delta)$, AG-1-IB (O), AG-1-IC $(\square)$, and the newly described AG-1-ID (ם). 
the Philippines (26). Further studies employing RFLP of rDNAITS and RAPD analyses confirmed that $R$. solani causing foliar blight of coffee belonged to AG-1-IA (27). In pathogenicity test, coffee isolates of $R$. solani causing necrotic leaf spot infected cucumber seedlings showing rot symptom as AG-1-IA, 1-IB, and 1-IC, indicating that these $R$. solani are not host specific on coffee. On the other hand, only coffee isolates infected coffee leaves showing necrotic symptom. Although isolates of AG-1-IA obtained from coffee were not included in pathogenicity test, it is assumed that isolates of AG-1-IA can infect coffee leaves. In artificial inoculation, isolates of AG-1-IA obtained from coffee infected corn leaves although the disease severity was lower than those of isolates of AG-1-IA obtained from corn, soybean, wheat, sugarcane, mungbean, rice, durian, sorghum, and itchgrass (26).

Coffee isolates were multinucleate, ranging from 3 to 12 nuclei per hyphal cell, and gave $\mathrm{C} 2$ anastomosis reactions with the tester isolates belonging to AG-1-IA, 1-IB, and 1-IC but not with tester isolates representing any other AG. Thus, the isolates from coffee belong to AG-1. Other characteristics support the finding that coffee isolates belong to AG-1. For example, hyphal growth rate at different temperatures of coffee isolates was similar with those of AG-1-IA, 1-IB, and 1-IC (10,11). In addition, coffee isolates were thiamine prototrophic as are AG-1-IA, 1-IB, and 1-IC (25). However, the colony morphology of coffee isolates was different from those of AG-1-IA, 1-IB, and 1-IC, as was mature colony

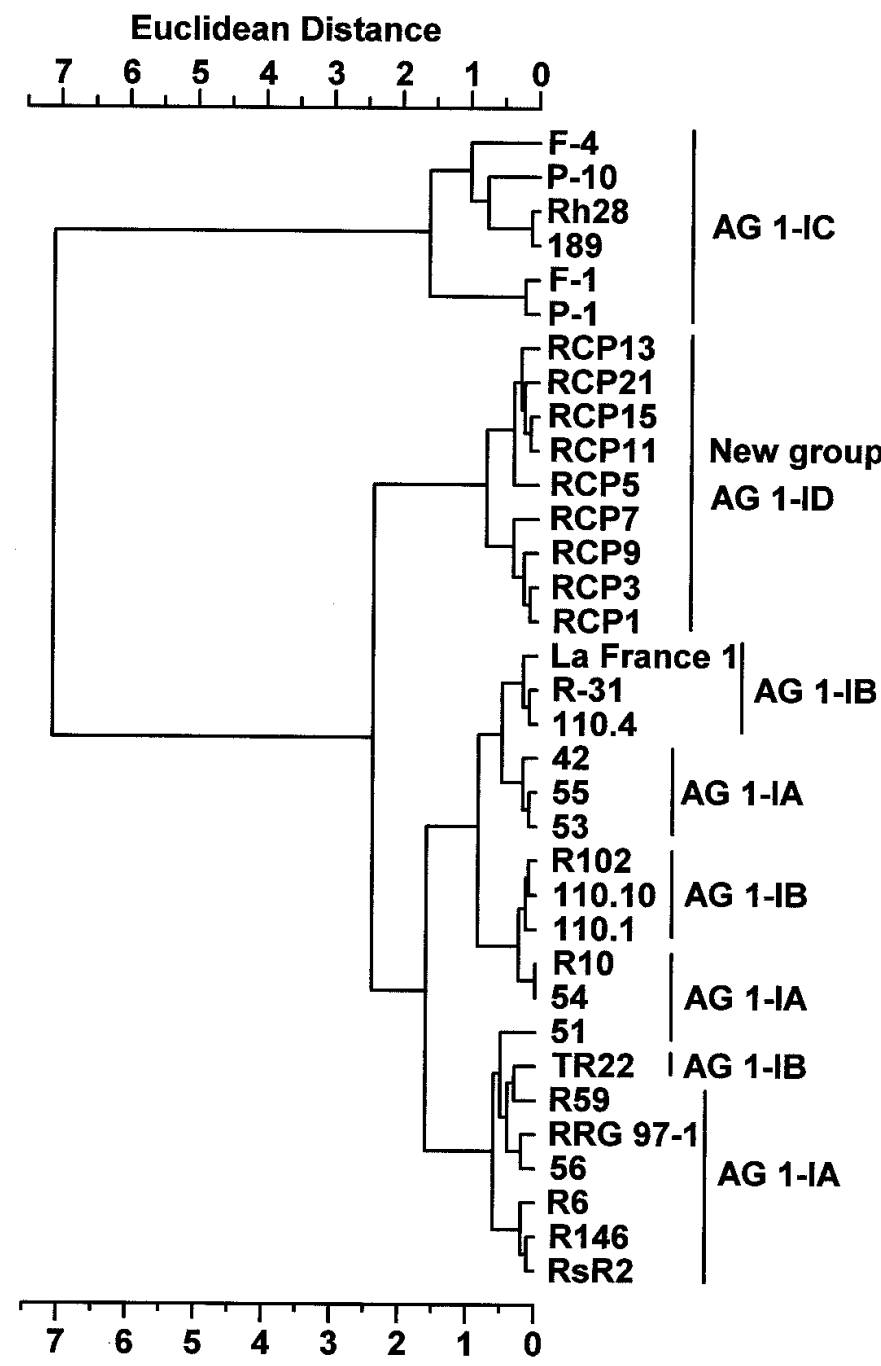

Fig. 5. Dendrogram of cluster analysis on Rhizoctonia solani anastomosis group 1 (AG-1-IA), 1-IB, 1-IC, and the newly described AG-1-ID based on fatty acid percent compositions. Identification of isolates described in Table 1. appearance and the distribution of sclerotia, which covered the surface of PDA.

Traditionally, AG-1 has been divided into three subgroups ( 9 , $11,24,31$ ) based on pathogenicity and cultural morphology. However, Liu and Sinclair (15) differentiated AG-1 into six intraspecific groups designated AG-1-IA, 1-IB, 1-IC, 1-ID, 1-IE, and 1 -IF based on RFLP of rDNA-ITS and isozyme compositions. The length of rDNA-ITS of AG-1-ID and AG-1-IF (15) was $720 \mathrm{bp}$ and AG-1-IE was $700 \mathrm{bp}$ (15), which were different from coffee isolates. Thus, the intraspecific groups ID, IE, and IF of AG-1 described by Liu and Sinclair (15) cannot be the same as the isolates of AG-1 from coffee reported in this study. Furthermore, genetic relatedness of their subgroups in AG-1 (15) was inconsistent because of small sample size (only one or two isolates) for identification of ID, IE, and IF. Moreover, the cultural morphology of each subgroup in their studies was not reported. It has been proposed that the term intraspecific group should not be used for classifying $R$. solani below species level because of some confused interpretation. Instead, the term subgroup is suggested (24).

In the RFLP analysis of rDNA-ITS using seven enzymes, coffee isolates had different size products than isolates of AG-1-IA, 1-IB, and 1-IC. Our results in RFLP analysis of isolates of AG-1IA, 1-IB, and 1-IC had similar banding pattern and fragment size with those reported by Liu and Sinclair (15) and Toda (36) using the same enzymes. Of the seven enzymes used, AluI was more applicable to distinguish coffee isolates from the three known subgroups of AG-1. The unique bands of 365,110 , and $65 \mathrm{~kb}$ clearly distinguished coffee isolates from isolates of AG-1-IA or AG-1-IC. The unique bands of 365 and $110 \mathrm{~kb}$ differentiated coffee isolates from isolates of AG-1-IB.

Many loci were evident with each primer used in the RAPD analysis (7). RAPD analysis gave valuable information about the degree of variability and the level of genetic relatedness among the 25 isolates representing the three known subgroups of AG-1 and the nine coffee isolates. A phylogenetic tree based on banding patterns of RAPD using six primers showed that coffee isolates were distinct from isolates of AG-1-IA, 1-IB, and 1-IC. Additionally, isolates from each subgroup of AG-1-IA, 1-IB, and 1-IC were clustered separately (Fig. 3). This result supported the differentiation among AG-1-IA, 1-IB, and 1-IC subgroups based on RAPD analysis previously reported by Toda (36). The results of our study revealed that RAPD is useful as a molecular approach for differentiation of genetic variability among AG-1 subgroups.

Ten fatty acids including myristic, pentadecanoic, palmitic, palmitoleic, heptadecanoic, 9-heptadecenoic, stearic, oleic, linoleic, and linolenic were present in isolates of AG-1 representing AG-1IA, 1-IB, 1-IC, and coffee isolates. Stevens-Johnk and Jones $(33,35)$ detected 12 fatty acids in isolates of $R$. solani AG-1. A similar study by Matsumoto et al. (17) detected nine fatty acids in the causal agent of sheath diseases on rice caused by Rhizoctonia spp. including $R$. solani AG-1-IA. The differences might be due to variation in isolates used, method of FAME extraction, or gas chromatography conditions. Linoleic was the major fatty acids found in all isolates of AG-1-IA, 1-IB, 1-IC, and coffee isolates. Stevens-Johnk and Jones $(33,35)$ also reported that percent composition of linoleic was higher than other fatty acids detected in isolates of AG-1. Percent composition of myristic, stearic, and linolenic between coffee isolates and AG-1-IA, 1-IB, and 1-IC suggest that these three fatty acids are useful for differentiating coffee isolates from AG-1-IA, 1-IB, and 1-IC. In contrast to the results of RFLP of rDNA-ITS and RAPD analyses, isolates of AG-1-IA and 1-IB were not clearly differentiated using fatty acid composition (Figs. 4 and 5). This result was in accordance with a study on fatty acid composition of AG-1 done by Stevens-Johnk and Jones (35).

Principal component and cluster analyses showed that coffee isolates were distinctly differentiated from isolates of AG-1-IA, 1-IB, and 1-IC (Figs. 4 and 5). The results of fatty acid analysis 
support the grouping of coffee isolates separately from AG-1-IA, $1-\mathrm{IB}$, and 1-IC based on cultural morphology, pathogenicity, RFLP of rDNA-ITS, and RAPD as previously described.

Based on the results of the study including cultural morphology, anastomosis behavior, hyphal growth rate, thiamine requirement, pathogenicity, analyses of RFLP of rDNA-ITS, RAPD, and fatty acid, we propose a new subgroup ID (AG-1-ID) for the $R$. solani AG-1 isolates, the causal agent of necrotic leaf spot of coffee.

\section{ACKNOWLEDGMENTS}

Financial assistance provided by the Ministry of Education, Culture, Sports, Science, and Technology (Monbukagakusho) Japan. We thank D. E. Carling, University of Alaska, for reviewing the manuscript; T. Asano, Gifu University, for statistical assistance; R. Yamauchi, Gifu University, for assistance with FAME analysis; and O.-A. Siaw for helping with the English in this paper.

\section{LITERATURE CITED}

1. Adams, G. C. 1988. Thanatephorus cucumeris (Rhizoctonia solani) a species complex of wide host range. Pages 535-552 in: Advances in Plant Pathology, Vol. 6. Genetics of Plant Pathogenic Fungi. G. S. Sidhu, ed. Academic Press, New York.

2. Baird, R. E., Gitaitis, R. D., Carling, D. E., Baird, S. M., Alt, P. J., and Mullinix, B. G. 2000. Determination of whole-cell fatty acid profiles for the characterization and differentiation of isolates of Rhizoctonia solani AG-4 and AG-7. Plant Dis. 84:785-788.

3. Bandoni, R. J. 1979. Safranin O as a rapid nuclear stain for fungi. Mycologia 71:873-874.

4. Carling, D. E. 1996. Grouping in Rhizoctonia solani by hyphal anastomosis reaction. Pages 37-47 in: Rhizoctonia Species: Taxonomy, Molecular Biology, Ecology, Pathology, and Disease Control. B. Sneh, S. Jabaji-Hare, S. Neate, and G. Dijst, eds. Kluwer Academic Publishers, Dordrecht, the Netherlands.

5. Carling, D. E., Baird, R. E., Kuninaga, S., and Gitaitis, R. D. 1999. Characterization of anastomosis group (AG) 13 of Rhizoctonia solani. (Abstr.) Phytopathology 89(suppl.):S11.

6. Carling, D. E., and Kuninaga, S. 1990. DNA base sequence homology in Rhizoctonia solani Kühn: Inter- and intragroup relatedness of anastomosis group-9. Phytopathology 80:1362-1364.

7. Duncan, S., Barton, J. E., and O'Brien, P. A. 1993. Analysis of variation in isolates of Rhizoctonia solani by random amplified polymorphic DNA assay. Mycol. Res. 97:1075-1082.

8. Hietala, A. M., Sen, R., and Lilja, A. 1994. Anamorphic and teleomorphic characteristics of a uninucleate Rhizoctonia sp. isolated from roots of nursery grown conifer seedlings. Mycol. Res. 98:1044-1050.

9. Hyakumachi, M., Mushika, T., Ogiso, Y., Toda, T., Kageyama, K., and Tsuge, T. 1998. Characterization of a new cultural type (LP) of Rhizoctonia solani AG 2-2 isolated from warm-season turfgrasses, and its genetic differentiation from other cultural types. Plant Pathol. 47:1-9.

10. Hyakumachi, M., and Sumino, A. 1984. New morphological type (IC) in Rhizoctonia solani AG 1 isolated from the sugar beet-manufactorywaste-soils and some of its characteristics. Ann. Phytopathol. Soc. Jpn. 50:507-514.

11. Jones, R. K., and Belmar, S. B. 1989. Characterization and pathogenicity of Rhizoctonia spp. isolated from rice, soybean, and other crops grown in rotation with rice in Texas. Plant Dis. 73:1004-1010.

12. Kangatharalingam, N., and Carson, M. L. 1988. Technique to induce sporulation in Thanatephorus cucumeris. Plant Dis. 72:146-148.

13. Kronland, W. C., and Stanghellini, M. E. 1988. Clean slide technique for the observation of anastomosis and nuclear condition of Rhizoctonia solani. Phytopathology 78:820-822.

14. Lee, S. B., and Taylor, J. W. 1990. Isolation of DNA from fungal mycelia and single spores. Pages 282-287 in: PCR Protocols: A Guide to Methods and Applications. M. A. Innis, D. H. Gelfand, J. J. Sninsky, and T. J. White, eds. Academic Press, New York.

15. Liu, Z. L., and Sinclair, J. B. 1993. Differentiation of intraspecific groups within anastomosis group 1 of Rhizoctonia solani using ribosomal DNA internal transcribed spacer and isozyme comparisons. Can. J. Plant Pathol. 15:272-280.

16. MacNish, G. C., Carling, D. E., and Brainard, K. A. 1993. Characterization of Rhizoctonia solani AG- 8 from bare patches by pectic isozyme and anastomosis techniques. Phytopathology 83:922-927.
17. Matsumoto, M., Furuya, N., and Matsuyama, N. 1997. Characterization of Rhizoctonia spp., causal agents of sheath diseases of rice plant by total cellular fatty acids analysis. Ann. Phytopathol. Soc. Jpn. 63:149-154.

18. Matsumoto, M., and Matsuyama, N. 1999. Grouping of isolates in AG 2 of Rhizoctonia solani by total cellular fatty acid analysis. Mycoscience 40:35-39.

19. Menzeis, J. D. 1970. Introduction: The first century of Rhizoctonia solani. Pages 3-5 in: Rhizoctonia solani: Biology and Pathology. J. R. Parmeter, Jr., ed. University of California Press, Berkeley.

20. Naito, S. 1996. Basidiospore dispersal and survival. Pages 197-206 in: Rhizoctonia Species: Taxonomy, Molecular Biology, Ecology, Pathology, and Disease Control. B. Sneh, S. Jabaji-Hare, S. Neate, and G. Dijst, eds. Kluwer Academic Publishers, Dordrecht, the Netherlands.

21. Naito, S., Mochida, H., Nakajima, T., and Ohto, Y. 1995. Infection with basidiospores of Thanatephorus cucumeris (AG 2-3 of Rhizoctonia solani) and development of soybean foliar blight lesions. Ann. Phytopathol. Soc. Jpn. 61:362-268.

22. Ogoshi, A. 1976. Studies on the grouping of Rhizoctonia solani Kühn with hyphal anastomosis, and on the perfect stage of groups. Natl. Inst. Agric. Sci. Bull. Ser. C, No. 3.

23. Ogoshi, A. 1987. Ecology and pathogenicity of anastomosis and intraspecific groups of Rhizoctonia solani Kühn. Annu. Rev. Phytopathol. 25:125-143.

24. Ogoshi, A. 1996. Introduction: The genus Rhizoctonia. Pages 1-9 in: Rhizoctonia Species: Taxonomy, Molecular Biology, Ecology, Pathology, and Disease Control. B. Sneh, S. Jabaji-Hare, S. Neate, and G. Dijst, eds. Kluwer Academic Publishers, Dordrecht, the Netherlands.

25. Ogoshi, A., and Ui, T. 1979. Specificity in vitamin requirement among anastomosis groups of Rhizoctonia solani Kühn. Ann. Phytopathol. Soc. Jpn. 45:47-53.

26. Pascual, C. B. 1999. Evaluation of host resistance and pathogenic variability of Rhizoctonia solani AG 1-IA in cereal crops. Ph.D. diss. The United Graduate School of Agricultural Science, Gifu University, Japan.

27. Pascual, C. B., Toda, T., Raymondo, A. D., and Hyakumachi, M. 2000. Characterization by conventional techniques and PCR of Rhizoctonia solani isolates causing banded leaf sheath blight in Maize. Plant Pathol. 49:108-118.

28. Priyatmojo, A., Toda, T., Pascual, C. B., Escopalao, V. E., Tangonan, N G., Kageyama, K., and Hyakumachi, M. 1997. Characterization of a new subgroup in AG 1 of Rhizoctonia solani isolated from coffee leaves. (Abstr.) Ann. Phytopathol. Soc. Jpn. 63:512.

29. Priyatmojo, A., Yamauchi, R., Kageyama, K., and Hyakumachi, M. 1998. Comparison of whole-cell fatty acid compositions of a new subgroup ID with other three known subgroups (IA, IB, and IC) of Rhizoctonia solani anastomosis group 1. (Abstr.) Ann. Phytopathol. Soc. Jpn. 64:622.

30. Sneath, P. H. A., and Sokal, R. R. 1973. Numerical Taxonomy: The Principles and Practice of Numerical Classification. W. H. Freeman \& Co., San Francisco.

31. Sneh, B., Burpee, L., and Ogoshi, A. 1991. Identification of Rhizoctonia Species. The American Phytopathological Society, St. Paul, MN.

32. Steel, R. G. D., and Torrie, J. H. 1980. Principles and Procedures of Statistics. McGraw-Hill Inc., New York.

33. Stevens-Johnk, J., and Jones, R. K. 1992. Determination of whole-cell fatty acids in isolates of Rhizoctonia solani AG-1-IA. Phytopathology 82:68-72.

34. Stevens-Johnk, J., and Jones, R. K. 1993. Differentiation of populations of AG 2-2 of Rhizoctonia solani by analysis of cellular fatty acids. Phytopathology 83:278-283.

35. Stevens Johnk, J., and Jones, R. K. 1994. Comparison of whole-cell fatty acid compositions in intraspecific groups of Rhizoctonia solani AG-1. Phytopathology 84:271-275.

36. Toda, T., Nasu, H., Kageyama, K., and Hyakumachi, M. 1998. Genetic identification of web-blight fungus (Rhizoctonia solani AG 1) obtained from European pear using RFLP of rDNA-ITS and RAPD analyses. Res. Bull. Fac. Agric. Gifu Univ. 63:1-9.

37. Tommerup, I. C., Barton, J. E., and O'Brien, P. A. 1995. Reliability of RAPD fingerprinting of three basidiomycete fungi, Laccaria, Hydnangium, and Rhizoctonia. Mycol. Res. 99:179-186.

38. Vilgalys, R., and Gonzales, D. 1990. Ribosomal DNA restriction fragment length polymorphisms in Rhizoctonia solani. Phytopathology 80:151-158.

39. White, T. J., Bruns, T., Lee, S., and Taylor, J. 1990. Amplification and direct sequencing of fungal ribosomal RNA genes for phylogenetics. Pages 315-322 in: PCR Protocols: A Guide to Methods and Applications. M. A. Innis, D. H. Gelfand, J. J. Sninsky, and T. J. White, eds. Academic Press, New York. 